\title{
Huge Anterior Lip Cervical Fibroma Presenting as Gynaecological Emergency: A Rare Case Report
}

\author{
Khanam D', Hakim $\mathrm{S}^{2}$, Parveen $\mathrm{S}^{3}$, Ali WM $\mathbf{M}^{4}$ \\ ${ }^{1}$ Dr. Deeba Khanam, Assistant Professor, Department of Obstetrics and Gynaecology, ${ }^{2}$ Prof. Seema Hakim, Professor \\ Department of Obstetrics and Gynaecology, ${ }^{3}$ Dr. Shazia Parveen, Assistant Professor Department of Obstetrics and \\ Gynaecology, ${ }^{4}$ Dr Wasif Mohammad Ali, MBBS, MS General Surgery, Assistant Professor Department of Surgery. All are \\ affiliated with J N Medical College, A.M.U Aligarh, U.P, India
}

Address for correspondence: Dr Deeba Khanam. Email: khanamdeeba@gmail.com

\begin{abstract}
Leiomyoma are the most common tumours of female pelvis. These are mostly composed of smooth muscle cells and variable amount of tissues from extracellular matrix. Most of the fibroids are located in body of uterus but only 1-2\% are located in cervix. We report a case of 35 year old female who presented to us with a big vaginal mass ,pain, difficulty in walking and excessive bleeding and clinically differential diagnosis of chronic inversion, infected cervical polyp, procidentia and cervical fibroid was made but after preoperative evaluation, surgery and histopathology report it was diagnosed as cervical fibroid. Pedunculated cervical fibroid is a rare entity and patient presenting in shock is unusual presentation as in our case where we did not have the time for proper investigation and immediate measures had to be taken for the management.
\end{abstract}

Keywords: Cervical fibroid, Leiomyoma, Vaginal Myomectomy, Ultrasound.

\section{Introduction}

Leiomyoma are the most common benign tumours of uterus and female pelvis. It is mostly composed of smooth muscle fibres and varying contents of collagen, elastin and proteoglycan[1].Its incidence in women is considered to be $50 \%$ but is about $70-80 \%$ in histological samples and ultrasonographic findings [2]. Most of the leiomyoma are present in the body of uterus and only 1$2 \%$ are present in cervix and that too in supravaginal part. [1]

\section{Case Report}

A 35 year old lady para one with live one presented to the emergency hall with complains of menorrhagia for 1 year ,mass per vaginum which slowly grew to the present size over 5 years, and excessive bleeding per vaginum since evening. On general examination pallor was presents, pulse rate was 100/minute, and BP was 98 systolic, febrile, with no dyspnoea or cyanosis.

Manuscript received: $20^{\text {th }}$ Nov 2014

Reviewed: $6^{\text {th }}$ Dec 2014

Author Corrected; $15^{\text {th }}$ Dec 2014

Accepted for Publication: $22^{\text {th }}$ Dec 2014
Abdominal examination was unremarkable with no abdominal swellings. Per speculum examination showed a mass measuring $20 \times 15 \times 10 \mathrm{~cm}$ in size, irregular, with dirty areas of necrosis and haemorrhage and bleeding profusely on touch, arising from anterior lip of cervix by a thick short pedicle about 1.5-2 inches in thickness. Posterior lip was very thin [Fig 1]. Uterus was bulky and uterine sound could be inserted in the cavity. As patient was bleeding profusely leading to deterioration of vitals, urgently 2 unit blood was transfused and patient was prepared for vaginal myomectomy/ hysterectomy.

The pedicle was clamped in small parts and the mass was resected. Haemostasis was achieved. 1 unit blood was transfused per operatively, and the procedure was successfully completed. Post operative course was uneventful, antibiotics were given and post op blood was transfused and patient was discharged in good condition after one week. Histopathology reported it to be leiomyoma with areas of degeneration and necrosis. 


\section{Discussion}

Leiomyoma are benign smooth muscle tumours of uterus. It usually originates from uterus and very rarely from cervix where its incidence is 1-2\% [1]. Giant cervical fibroids and that too isolated with no other uterine fibroid are very difficult to find. These tumours are more common in Africans and are 4 times more prevalent compared to Caucasians [3]. These are considered to be estrogens and progesterone dependent [4].Uterine leiomyoma on gross examination show whorled appearance due to the arrangement of smooth muscles. They can be easily distinguished from surrounding myometrium although it is non capsulated provided it has not undergone any kind of degenerative process. Cervical fibroids originate from smooth muscle cells of cervical wall and have similar histopathology as that of rest of uterus. Cervical fibroids are mostly restricted to cervical canal and very rarely they enlarge to an extent that they hang out of cervical canal .Till date the largest tumour weighing $65 \mathrm{~kg}$ has been reported by Hunt in 1888 [5].

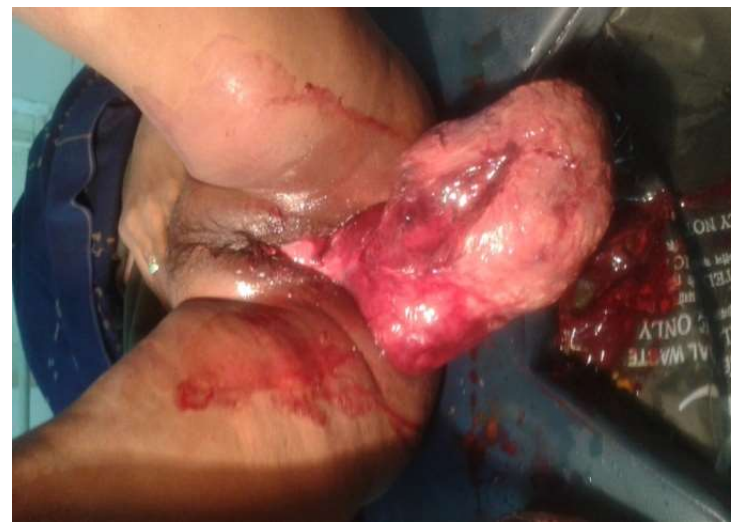

Fig 1: Cervical fibroid arising from anterior lip of cervix

Cervical fibroids are classified as anterior, posterior, lateral and central and present with symptoms in accordance with the site of fibroid . They can distort the uterine cavity. Anterior fibroids may present with urinary symptoms ,posterior may present with difficulty passing stools, lateral would extend to broad ligament and central fibroid pushes the uterus upwards and appears as 'lantern on the top of St Paul's'[6]. It can also present with menstrual irregularities, post coital bleeding, lower abdominal pain and dysparunia.

USG has been considered the primary diagnostic tool. MRI increases the precision to which number, size, and location of myomas are identified and has more sensitivity than ultrasound, can identify leiomyoma, adenomyosis and diffuse leiomyomatosis. MRI is considered best for preoperative evaluation and planning the route of myomectomy [7]. CT scan has less value in this regard.

Cervical fibroids are difficult to manage, mostly because of inaccessibility, distortion of anatomical structures and hence increased risk of damaging uterine vessels, ureter and bladder [8].The kind of incision on fibroid has to be planned as vertical incision owing to its proximity to uterus can damage bladder, horizontal incision can cut the vessels as the direction is perpendicular to the vessels, leading to haemorrhage [9]. Preoperative evaluation is important in deciding the route and procedure of choice. Cervical fibroid inside the cervical canal and with major part towards the body of uterus can be approached abdominally, and the one growing outside the cervical canal can be operated vaginally. [10]

Hysterectomy/ Myomectomy is done when the patient is symptomatic and only when the medical management fails. Recently uterine artery embolisation is done to treat myomas. [11].

The present case is a very rare case of a giant cervical fibroid and mimics uterine inversion, procidentia cervical polyp which were considered in differential diagnosis. The presence of bulky uterus on per vaginal examination ruled out the first 2 possibilities and histopathology was required to differentiate between the polyp and fibroid. This case being rare owing to its large size and presentation of excessive bleeding which resulted in shock, thereby preventing any investigating modality, and immediate surgical procedure was required. As the mass was pedunculated so it could be a possibility that 
leiomyoma arising from cervix moved out as a polyp with its pedicle attached to anterior lip of cervix. Histopathological examination showed areas of whorled appearance and hyaline degeneration.

\section{Conclusion}

Thus we conclude that cervical fibroids can have variable presentations, it can grow upwards towards the body of uterus and present as an abdominal mass, stay inside the cervical canal as a pelvic mass or although rare can come out through cervical canal to become pedunculated cervical fibroid as in our case, so this possibility should also be kept in mind when patient presents with a pedunculated vaginal mass. Preoperative evaluation of the mass is important for planning proper route of approach and to decide the required procedure.USG is the first and MRI is the best diagnostic tool for detecting number, size and location of fibroids. When ideal circumstances are not available and the patient presents with profuse bleeding and shock, then a proper examination under general anaesthesia before the operative procedure has to be done to decide the route and procedure of choice.

\section{References}

1. Bhatla N. Tumous of the corpus uterine: Jeff Coate's principles of Gynaecolgy 5th edition London, Arnold Publisher. 2001; 407.

2. Buttram VC Jr, Reiter RC. Uterine leiomyomata: etiology, symptomatology, and management. Fertil Steril. 1981 Oct;36(4):433-45.

3. Faerstein E, Szklo M, Rosenshein N. Risk factors of uterine Leiomyoma: A practice-based case-control study. African-American, Heritage, reproductive history, body size, and smoking. Am J Epidemiol. 2001 Jan $1 ; 153(1): 1-10$.

4. Van Voorhis BJ, Romitti PA, Jones MP. Family history as a risk, Factor for development of uterine leiomyomas: result of a pilot Study. J Reprod Med. 2002 Aug;47(8):663-9.

5. T. Evans III, J.H. Pratt. A giant fibroid uterus. Obstet Gynecol. 1979 Sep;54(3):385-6.

6. Monaghan JM, Lopes AB, Naik R. Total hysterectomy for cervical and broad ligament fibroids. In: Huxley R, Taylor S, Chandler K, editors.Bonney's gynaecological surgery 10th ed. Blackwell Publishing. 2004; 74-86

7. Leley L, Breech and John A. Rock Te Linde's Operative Gynaecology In: leiomyomataUteri and Myomectomy, 10 Ed. 2014; Chapter 31: 687-724.

8. Kaur A.P. et al. Huge cervical fibroid: Unusual presentation,. The Journal of Obstetrics \& Gynaecology of India 2002. Jan-Feb; 52(1) : 164-165

9. Swati Singh, Priyakshi Chaudhary. International Journal of Reproduction, Contraception, Obstetrics and Gynecology . Int J Reprod Contracept Obstet Gynecol. 2013 Dec;2(4):687-688

10 Dr. Surana Akash Dilip, Dr. Gautam .S. Aher, Dr. Urmila Gavali. Huge Fibroid-Polyp: A Case Report Sch J Med Case Rep 2014; 2(2):78-79.

11. Tanweer Karim, Kundan Patil,Anuradha Pancha, Chandramauli Basu . Presentation and management of giant fibroid uterus in an adolescent girl. Open Access Surgery 2010:3 13-15

\section{How to cite this article?}

Khanam D, Hakim S, Parveen S, Ali WM. Huge Anterior Lip Cervical Fibroma Presenting as Gynaecological Emergency: A Rare Case Report. Int J Med Res Rev 2015;3(1):115-117. doi:10.17511/ijmrr.2015.i1.19 